\title{
A transfer analysis of the repetition effect in the lexical and ambiguity decision tasks
}

\author{
DAVID S. GORFEIN \\ Adelphi University, Garden City, New York \\ and \\ ANDREA BUBKA \\ St. Peter's College, Jersey City, New Jersey
}

\begin{abstract}
Two experiments were performed in an attempt to evaluate explanations of repetition primingthe facilitation observed when the same word is processed a second time in the same task. One task employed was lexical decision (word/nonword) and the other was ambiguity decision (ambiguous/unambiguous). In the first experiment, transfer on a lexical decision task was measured following either a lexical decision or an ambiguity decision. When the identical lists were processed in the first phase for lexical and ambiguity decision, equal repetition effects were obtained on lexical decision. However, when the ambiguity task was presented without nonwords, no repetition priming occurred. In a second experiment, the within-task repetition effect was large for the ambiguity decision, whereas no transfer was obtained from lexical decision to ambiguity decision. The results were interpreted as being consistent with a transfer-appropriate processing account of repetition priming.
\end{abstract}

The second presentation of even a common word has been shown to enhance the identification of that word in a variety of tasks (Tenpenny, 1995). Repetition effects for words have been studied by employing the lexical decision task since 1974 (see, e.g., Forbach, Stanners, \& Hochhaus, 1974; Scarborough, Cortese, \& Scarborough, 1977). Tenpenny has argued for an episodic memory component in theories of repetition effects in word identification. Specifically, the three principal theoretical positions with regard to repetition effects in the lexical decision task can be classified as varieties of episodic memory positions (Masson \& Freedman, 1990).

One theoretical view, the transfer-appropriate processing view, has emphasized the benefit due to a repetition of (or memory for) the cognitive operations by which a word is processed (Jacoby, 1983a, 1983b; Kolers, 1975; Kolers \& Roediger, 1984; Masson \& MacLeod, 1992; Roediger \& Blaxton, 1987). According to this position, to the degree that operations are repeated, the recurrence of a word will result in enhancing the speed and/or accuracy of processing that word. To the degree that operations performed on a word in two different occurrences are not the same, we would expect an absence of facilitation.

A preliminary version of this paper was presented at the annual meeting of the Midwestern Psychological Association, Chicago, 1994. The authors gratefully acknowledge the helpful comments of Annette deGroot, Jim Erickson. Kim Kirsner, Gordon Logan, and Roddy Roediger on earlier versions of this manuscript. Correspondence should be addressed to D. S. Gorfein, Department of Psychology, Box 19528, University of Texas, Arlington, TX 76019-0528 (e-mail: gorfein(a) utarlg.uta.edu),
The conceptual meaning hypothesis was developed to address contextual manipulations such as those created by relatedness priming in lexical decision, in which a change in a prime's meaning results in little or no facilitation (Bainbridge, Lewandowsky, \& Kirsner, 1993; Lewandowsky, Kirsner, \& Bainbridge, 1989; Masson \& Freedman, 1990). In other words, facilitation due to repetition will be reduced if the conceptual meaning is not instantiated on each occurrence.

A third position is based on an extension of the episodic retrieval explanation of automaticity in attention (Logan, 1988), to lexical decision (Logan, 1990). According to this view, a lexical decision may be made by accessing the lexicon and seeing whether an item has sufficient meaning to be called a word. However, if a decision has previously been made about a particular word, the lexical decision may be made by retrieving a proposition like “__ is a word." Each time a decision is made, such a proposition is stored in memory. Employing a race model, Logan predicted that repetitions of the same word will tend to result in faster responses.

Logan (1988) reported an experiment in which study participants first evaluated a word with respect to the question, "Is this item pronounceable?" and later made a lexical decision to it. No transfer was obtained. As an explanation, Logan focused on the different response requirements of the two tasks. In effect, retrieving the fact that something is pronounceable does not make it a word, although the opposite may be true. However, from the transfer-ofoperations viewpoint, it may also be the case that different operations underlie pronunciation decision and lexical decision. At a minimum, phonological decisions do not require the use of the lexicon (see Paap, 1991). 
In the present experiments, we employed a design similar to that of Logan (1988). As the alternative to lexical decision, we used ambiguity decision - a task that clearly must involve accessing the lexicon. Ambiguity decision requires a response to the question, "Does this item have two or more distinct meanings in English?" According to Forster and Bednall (1976), ambiguity decisions and lexical decisions require similar processing of items, but the former also require the decision that a word has two meanings.

In Experiment 1, we employed either ambiguity decision (different-task transfer condition) or lexical decision (same-task transfer condition) for Phase 1. This was followed by Phase 2 lexical decision. We used a similar design in Experiment 2, but used ambiguity decision as the Phase 2 task. In each experiment, materials in Phase 1 consisted of a mixture of homographic words, unambiguous words, and nonwords. The same items and an equal number of new items, which served as nontransfer controls, were presented in Phase 2.

In Experiment 1, we examined theories of repetition effects in lexical decision to see how well they predicted transfer from ambiguity decision to lexical decision. The theories all predict transfer from Phase 1 lexical decision words to the same items in Phase 2. For transfer from ambiguity to lexical decision, there are several possible outcomes.

The transfer-appropriate processing view predicts positive transfer from ambiguity decision to lexical decision similar to that from Phase 1 lexical decision, since both lexical decisions and ambiguity decisions involve accessing and evaluating entries in the internal lexicon. The conceptual meaning hypothesis could predict less transfer for homographs from first-list lexical decisions if transfer depends on whether in lexical decision access of the same meaning is instantiated. However, Bainbridge et al. (1993, p. 624) argued, "Because the customary meaning will, on average, be activated each time a word is presented in isolation, repetition of isolated words facilitates processing." Under this argument, both ambiguity and lexical decision should result in transfer to the Phase 2 lexical decision.

In Logan's (1988) retrieval model, the nature of what is retrieved is crucial, and what is retrieved is dependent on what is stored. Both homographs and nonhomographs are words. However, the answer to the question, "Does this item have two or more distinct meanings?" is "yes" for homographs and "no" for both unambiguous words and nonwords. This fact could lead to differential transfer. The response stored could be either the actual answer "yes" or "no" or a proposition such as " is a word." If the response is "yes" or "no," we might expect difficulty for unambiguous words, for which the participant will likely respond "no" on ambiguity decision, because these words do not have two meanings. In the more likely case that the episodic retrieval involves recovery of a proposition " is a word," we note that there is no requirement for the participant to make this decision on the Phase 1 ambiguity decision.
Perhaps in an ambiguity task that includes nonwords, as ours does, participants may first make a lexical decision to the item and then go on to answer the ambiguity question for items classified as words. To control for this possibility, we employed two ambiguity-to-lexical-decision transfer conditions in Phase 1, with one list including nonwords and the other excluding nonwords. If individuals respond to the presence of nonwords by making a lexical decision prior to the ambiguity decision, we would expect greater transfer from the Phase 1 ambiguity condition that includes nonwords.

\section{EXPERIMENT 1}

\section{Method}

Participants. Ninety-six Adelphi University students participated in this experiment to fulfill course requirements. Participants were assigned to one of three study conditions, with a common transfer task. in a counterbalanced fashion.

Design. Three conditions were employed in the study phase. Phase 1 conditions were followed by a common Phase 2 lexical decision task. Some Phase 1 participants made lexical decisions to each item prisented. Others made ambiguity decisions to the same items. In a second ambiguity condition, nonwords were not employed in the first phase, but the words used were identical to those in the other two conditions.

Twenty-eight balanced homographs ranging in the dominance of the primary meaning from .50 to $.73(M=63)$ were chosen from the Gorfein, Viviani, and Leddo (1982) norms. For each of these words. a highly unbalanced homograph (dominance $>.85$ ) was selected to match as closely as possible the frequency of the word in print (Kucera \& Francis, 1967). In addition, 112 unambiguous words were selected to match the homographs for frequency, two for each of the homographs. One of each of these words was changed to an orthographically permissible nonword by alteration of a single letter.

The 28 items in the balanced homograph set were divided to achicrc two subsets approximately equal in homograph balance and word frequency. The corresponding paired items in the unbalanced homograph. unambiguous words. and nonword lists were similarly divided. This created two lists, A and B. The A and B lists were employed cqually often in the first, or study, phase of the experiment. In the second. or transfer, phase, the combined A and B lists were used. Therefore, each critical item (homograph. unambiguous word) appeared as a repeated item for half the participants and a new (nonstudied) item for half of the participants. There were a total of 168 trials on the test lists: two thirds of the lists were words.

Procedure. In their consent form, participants were informed that they could be judging ambiguity ("Does this item have two or more distinct meanings?") or lexicality ("Is this an English word?".). Participants were tested individually, seated in a cubicle in front of a computer terminal with the " 1 " and " 2 " keys marked "no" and "yes" respectively. Participants were permitted to use either hand but were told to keep a finger resting on each of the response keys. Participants in the ambiguity task were asked to press the "yes" key if the item had two or more distinct meanings in English and to press the "no" hey if it latd one or no meaning. The homograph curdinal was presented as an illustration. For the lexical decision task, participants were told to judye whether the item presented was a word or a nonword. All subjects were given 10 practice items. Subjects were told to try to respond as quickly as was consistent with being $100^{\circ}$ o correct. During practice, fecdhach was given in the event of an error.

Each trial began with a $500-$ msec ready signal (4ttits). The tirect item was then presented and remained on the screen until a response was made or a time limit exceeded. The target-to-target stimulum nnect asynchrony (SOA) was constant for each list condition. For lexical decisions, the time limit was 2,000 msec, creating a 2,500 -moce SO. 1 . In Phase 1 , a time limit of 4,000 msec was employed for ambiguity decisions because this task is more difficult than lexical decision. Thi created an SOA of 4.500 msec for the ambiguity task. Items mere pre- 
sented in a different random order for each participant, using the MEL randomization procedure (Schneider, 1988).

After practice, participants completed the Phase 1 trials. The Phase 1 list consisted of 84 trials ( 28 homographs, 28 unambiguous words, and 28 nonwords) for the lexical decision and for the ambiguity decision task that included nonwords. The ambiguity condition without nonwords had 56 trials. The experimenter returned and gave instructions for the Phase 2 lexical decision task and presented a practice set of items. No mention was made of the relationship between lists; the lexical decision instructions were used. The experimenter left the room while participants performed the lexical decision transfer task on the full list of 168 items

\section{Results}

Reaction times (RTs) were analyzed for correct responses only on the transfer list. The log of each RT was computed to help normalize the data. Means were calculated for each within-subjects condition. These means were converted to antilogs and used for the statistical analyses. Alpha was set at .05 .

For the transfer list, a $3 \times 3 \times 2$ mixed model analysis of variance (ANOVA) was employed. There was one between-groups variable (three levels of Phase 1 task: lexical decision and ambiguity decision with and without nonwords), and there were two within-groups variables (three levels of word type [balanced homographs, unbalanced homographs, and unambiguous word] $\times$ two levels of repetition [repetition vs. first occurrence of target word]). The means for these conditions, along with the computed repetition effect (first occurrence RT repetition RT) are reported in Table 1.

Of interest was whether the effect of item repetition would be influenced by the Phase 1 task. An interaction of Phase 1 task $\times$ repetition was obtained $[F(2,93)=$ $\left.10.35, M S_{\mathrm{e}}=37,373.4\right]$. There was a repetition effect of $(34.8 \mathrm{msec})$ in the Phase 1 lexical decision task condition, and of $41 \mathrm{msec}$ in the condition in which participants in Phase 1 made ambiguity decisions to nonwords. However, the mean repetition effect was $-8.5 \mathrm{msec}$ when the ambiguity task did not include nonwords.

All main effects were significant. Repeated words were responded to $22.4 \mathrm{msec}$ faster than new words $[F(1,93)=$ $\left.21.45, M S_{\mathrm{e}}=3,373.4\right]$. The Phase 1 ambiguity task in the absence of nonwords condition yielded slower Phase 2 lexical decisions $(710 \mathrm{msec})$ than did either of the other two Phase 1 groups-lexical decision $(651 \mathrm{msec})$ and ambiguity with nonwords present $(659 \mathrm{msec})$. With respect to materials, responses were quicker to unbalanced homographs (659 msec) and balanced homographs (668 $\mathrm{msec})$ than to unambiguous words $(693 \mathrm{msec})[F(2,186)=26.5$, $\left.M S_{\mathrm{e}}=1,663.4\right]$. Neither of the other two-way interactions approached significance $(F \mathbf{s}<1)$, but there was a marginally significant three-way interaction $[F(4,186)=$ $\left.2.41, M S_{\mathrm{e}}=1,617.2, p<.06\right]$.

The same form of ANOVA was employed for accuracy scores. Both the main effect of repetition $[F(1,93)=$ 13.47] and the repetition effect $\times$ Phase 1 task interaction $\left[F(2,93)=7.66, M S_{\mathrm{e}}=.0017\right]$ were significant. Overall, repeated words (.971) were responded to more accurately than new words (.958), but the performance in the Phase 1 nonword-absent ambiguity condition was slightly poorer $(-.006)$ on repeated words. The only other significant effect for the accuracy analysis was that of word type $\left[F(2,186)=35.83, M S_{\mathrm{e}}=.002\right]$. Homographs (balanced .977 and unbalanced .975) were responded to more accurately than were unambiguous words (.942). There was no evidence of a speed-accuracy tradeoff.

A separate ANOVA showed no transfer for nonwords; no effect approached significance. The mean RT for those who had seen the nonwords in the Phase 1 lexical decision task was $799 \mathrm{msec}$ for repeated nonwords and $798 \mathrm{msec}$ for new nonwords. In the ambiguity-to-lexical decision transfer condition, the mean for repeated nonwords was $826 \mathrm{msec}$; that for new items was $814 \mathrm{msec}$.

In summary, similar transfer was obtained from Phase 1 lexical decisions and from ambiguity decisions when nonwords were included, but there was a complete absence of transfer when the Phase 1 ambiguity decision task did not include nonwords. Such a result suggests that repetition transfer is dependent not on similarity in access processes during lexical and ambiguity tasks, but on participants' making covert lexical decisions in the ambiguity task when the lists contain nonwords.

The results can be rendered compatible with the processing view only if we assume that the kind of processing items are given depends on the list materials and not on the task alone. Compatibility with the retrieval view depends on the participant's storing the proposition that an item is a word. Logan (personal communication, 1995) suggested that "lexical decision could be made by determining whether or not a letter string retrieves a meaning. Letter strings that retrieve meanings are words; ones that don't are nonwords." With respect to the Phase 1 ambiguity task, he added, "Prior training on ambiguity decisions could result in propositions like "has more than one meaning,' 'has only one meaning,' and 'has no meaning' which could be used to justify subsequent lexical decision on the second presentation." Clearly, this position would predict that transfer would be obtained whether or not the list contained nonwords. This was not the case. How the proponents of the conceptual meaning view would handle the outcome of the experiment is unclear. Nothing in that approach would serve to distinguish between the ambiguity task with or without nonwords.

\section{EXPERIMENT 2}

Although we were unable to find published research on repetition priming in the ambiguity decision task, a test of transfer in that task seemed quite useful. A processing view that emphasizes repetition of operations would predict repetition priming within the ambiguity task but less or no transfer from the lexical decision to the ambiguity task. This follows because in the lexical task, lexical search can be terminated when a single meaning of a word is found producing a partial matching of the operations necessary to decide if a word has two meanings. An absence of transfer from the lexical decision task would be predicted by an episodic retrieval view, as propositions stored about items following lexi- 


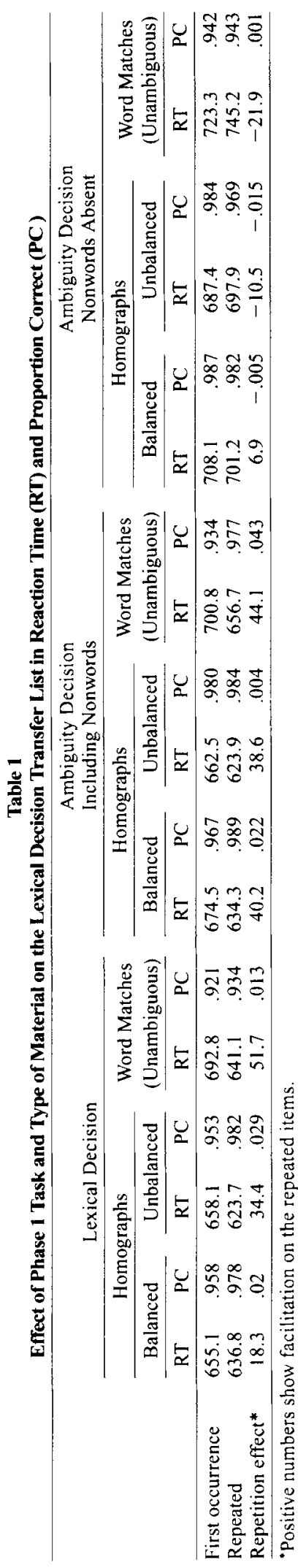

cal decision (“" is a word") would be insufficient to aid in the ambiguity decision.

\begin{abstract}
Method
Participants. Participants in this study, which was conducted concurrently with Experiment 1, were 64 Adelphi University students. None served in both experiments. Participants were assigned to conditions using a counterbalancing procedure.

Design. Two study conditions were employed, followed by a common transfer task. In the study phase, participants in one condition made lexical decisions to each item presented. In the other condition, ambiguity decisions were made. All participants then received the same ambiguity decision task and list.

Materials. Materials were the same as those in Experiment 1 except that the first list omitting nonwords was not employed. The 168 trials on the test list had 56 nonwords and 56 unambiguous words, both of which required "no" as an answer; the other 56 trials used homographs requiring a "yes" response.

Procedure. The procedure and instructions were the same as in Experiment 1 . The Phase 1 lexical decision task employed a 2,000-msec RT limit, whereas $4,000 \mathrm{msec}$ were allowed for the responses in the ambiguity decision task in both phases.
\end{abstract}

\title{
Results
}

The same form of analysis as that in Experiment 1 was performed. A mixed model $2 \times 3 \times 2$ ANOVA was employed, since this design included only two levels of the Phase 1 task. The condition means are reported in Table 2.

No cross-task transfer was obtained in this study. In Phase 2, the repetition effect was $295.3 \mathrm{msec}$ for those in the first-list ambiguity condition. It was $2.6 \mathrm{msec}$ for those in the Phase 1 lexical decision group, resulting in a Phase 1 task $\times$ repetition interaction $[F(1,62)=48.84]$. Both balanced $(1,308 \mathrm{msec})$ and unbalanced homographs $(1,397 \mathrm{msec})$ were responded to faster than unambiguous words $(1,504 \mathrm{msec})\left[F(2,124)=19.11, M S_{\mathrm{e}}=\right.$ $64,505]$. The effect of materials did not interact with either of the other independent variables.

A corresponding analysis of accuracy data showed, as expected, that balanced homographs (.785) were responded to more accurately than either unambiguous words $(.669)$ or unbalanced homographs $(.614)[F(2,124)$ $\left.=15.28, M S_{\mathrm{e}}=.064\right]$. With respect to the repetition effect, there was a repetition $\times$ Phase 1 task interaction effect $\left[F(1,62)=4.57, M S_{\mathrm{e}}=.009\right]$. Although there was an improvement in accuracy for repeated items following Phase 1 ambiguity decisions (.037), there was none following Phase 1 lexical decisions (-.004).

The predictions of repetition transfer for ambiguity decisions are similar for processing models and the episodic memory retrieval model. Both predict positive transfer from the Phase 1 ambiguity task and little or no repetition effect from Phase 1 lexical decisions. We found a very large repetition effect in the ambiguity condition for both RT and accuracy. In contrast, the processing of words in the Phase 1 lexical decision task failed to transfer to the ambiguity task.

With respect to nonwords, the data were surprising. Both the Phase 1 ambiguity condition (51 msec) and the Phase 1 lexical decision group $(41 \mathrm{msec})$ showed repetition effects for nonwords $\left[F(1,62)=10.15, M S_{\mathrm{e}}=\right.$ 
Table 2

Effect of Phase 1 Task and Type of Material on the Ambiguity Decision Transfer List in Reaction Time (RT) and Proportion Correct (PC)

\begin{tabular}{|c|c|c|c|c|c|c|c|c|c|c|c|c|}
\hline & \multicolumn{6}{|c|}{ Ambiguity Decision First } & \multicolumn{6}{|c|}{ Lexical Decision First } \\
\hline & \multicolumn{4}{|c|}{ Homographs } & \multirow{2}{*}{\multicolumn{2}{|c|}{$\frac{\text { Word Matches }}{\text { (Unambiguous) }}$}} & \multicolumn{4}{|c|}{ Homographs } & \multirow{2}{*}{\multicolumn{2}{|c|}{$\begin{array}{l}\text { Word Matches } \\
\text { (Unambiguous) }\end{array}$}} \\
\hline & \multicolumn{2}{|c|}{ Balanced } & \multicolumn{2}{|c|}{ Unbalanced } & & & \multicolumn{2}{|c|}{ Balanced } & \multicolumn{2}{|c|}{ Unbalanced } & & \\
\hline & RT & $\mathrm{PC}$ & RT & $\mathrm{PC}$ & RT & $\mathrm{PC}$ & RT & $\mathrm{PC}$ & RT & $\mathrm{PC}$ & RT & $\mathrm{PC}$ \\
\hline First & $1,442.1$ & .766 & 1,543 & .554 & $1,559.6$ & .710 & 1,3 & .772 & 1 & .654 & $1,566.3$ & .637 \\
\hline Repeated & $1,133.6$ & .804 & $1,196.7$ & .623 & $1,329.6$ & .702 & $1,323.3$ & .799 & $1,427.4$ & .627 & $1,559.1$ & .625 \\
\hline Repetition effect* & 308.5 & .038 & 347.1 & .069 & 230.0 & -.008 & 8.1 & .027 & -7.5 & -.027 & 7.2 & -.012 \\
\hline
\end{tabular}

*Positive numbers show facilitation on the repeated items.

67,867]. The size of the nonword repetition effect was much smaller than that for words following Phase $1 \mathrm{am}$ biguity judgments. No other effect for nonwords approached significance. Nonword RT in Phase 2 was $938 \mathrm{msec}$ for the Phase 1 ambiguity group and $971 \mathrm{msec}$ for the Phase 1 lexical group.

\section{DISCUSSION}

In combination, the two experiments show that repetition priming occurs for ambiguity decisions as well as for lexical decisions. Making a first decision about a word speeds the same decision later. With respect to transfer across tasks, an asymmetric pattern was obtained. There was complete transfer from Phase 1 ambiguity decisions to lexical decisions, but only if the Phase 1 list included nonwords. No transfer from Phase 1 lexical decisions to Phase 2 ambiguity decisions was obtained.

None of the three theories considered predicted the pattern of results obtained. All three can account for repetition effects on lexical decisions. The conceptual meaning view has no mechanism that applies to ambiguity decisions. As such, it remains a tenable model for lexical decisions, but lacks in generality. The retrieval model, which has been shown to have wide generality within a number of cognitive tasks, ap parently depends on the retrieval of exact propositions. If this model is correct, participants in the Phase 1 ambiguity task without nonwords in Experiment 1 are unable to translate propositions of the form " has a meaning" into " is a word."

Models that make transfer dependent on repetition of cognitive processes cannot be rejected. However, the transfer-appropriate processing model fails to specify in advance when appropriate processing will be engaged, rendering it almost untestable. It fails to predict such cases as that in Experiment 1, where transfer to the lexical decision task depended on whether the Phase 1 ambiguity decision list included or did not include nonwords. In a similar manner, the model is predictively silent with respect to any overlap of cognitive operations that occurs when words are judged first for lexicality and then for ambiguity. Nevertheless, although it awaits more specificity, it seems to be the best model of repetition prim:ng at this time.

\section{REFERENCES}

Bainbridge, J. V., LewANdowsky, S., \& KirSner, K. (1993). Competition effects in repetition priming are sense effects. Memory \& Cognition, 21, 619-626.

Forbach, G., Stanners, R., \& Hochhaus, L. (1974). Repetition and practice effects in a lexical decision task. Memory \& Cognition, 2, 337-339.
Forster, K. I., \& BeDNALl, E. S. (1976). Terminating and exhaustive search in lexical access. Memory \& Cognition, 4, 53-61.

Gorfein, D. S., Viviani, J. M., \& LEDDO, J. (1982). Norms as a tool for the study of homography. Memory \& Cognition, 10, 503-509.

JACOBY, L. L. (1983a). Perceptual enhancement: Persistent effects of an experience. Journal of Experimental Psychology: Learning, Memory, \& Cognition, 9, 21-38.

JACOBY, L. L. (1983b). Remembering the data: Analyzing interactive processes in reading. Journal of Verbal Learning \& Verbal Behavior, 22, 485-508.

KOLERS, P. A. (1975). Specificity of operations in sentence recognition. Cognitive Psychology, 1, 289-306.

Kolers, P. A., \& Roediger, H. L., III (1984). Procedures of mind. Journal of Verbal Learning \& Verbal Behavior, 23, 425-449.

KuČERA, H., \& FranCIS, W. (1967). Computational analysis of presentday American English. Providence, RI: Brown University Press.

Lewandowsky, S., Kirsner, K., \& Bainbridge, J. V. (1989). Context effects in implicit memory: A sense-specific account. In S. Lewandowsky, J. C. Dunn, \& K. Kirsner (Eds.), Implicit memory: Theoretical issues (pp. 185-198). Hillsdale, NJ: Erlbaum.

LOGAN, G. D. (1988). Toward an instance theory of automatization. Psychological Review, 95, 492-527.

LOGAN, G. D. (1990). Repetition priming and automaticity: Common underlying mechanisms? Cognitive Psychology, 22, 1-35.

Masson, M. E. S., \& FreEdman, L. (1990). Fluent identification of repeated words. Journal of Experimental Psychology: Learning, Memory, \& Cognition, 16, 355-373.

Masson, M. E. S., \& MacLeod, C. M. (1992). Reenacting the route to interpretation: Enhanced perceptual identification without prior perception. Journal of Experimental Psychology: General, 121, 145176.

PAAP, K. R. (1991). Dual-route models of print to sound: Still a good horse race. Psychological Research, 53, 13-24.

RoEDIGER, H. L., III. \& BLAXTON, T. A. (1987). Retrieval modes produce dissociations in memory for surface information. In D. S. Gorfein \& R. R. Hoffman (Eds.), Memory and learning: The Ebbinghaus Centennial Conference (pp. 349-379). Hillsdale, NJ: Erlbaum.

Scarborough, D. L., Cortese, C., \& Scarborough, H. (1977). Frequency and repetition effects in lexical memory. Journal of Experimental Psychology: Human Perception \& Performance, 3, 1-17.

SCHNEIDER, W. (1988). Micro Experimental Laboratory: An integrated system for IBM PC compatibles. Behavior Research Methods, Instruments, \& Computers, 20, 206-217.

TENPENNY, P. L. (1995). Abstractionist versus episodic theories of repetition priming and word identification. Psychonomic Bulletin \& Review, 3, 339-363.

(Manuscript received March 18, 1995:

revision accepted for publication December 27, 1996.) 